\title{
Prof Lee Yong Kiat, SMA Honorary Member: Physician, Teacher, Administrator, Medical Historian and Wise Man (8 October 1928 - 22 April 2013)
}

By Prof Fock Kwong Ming

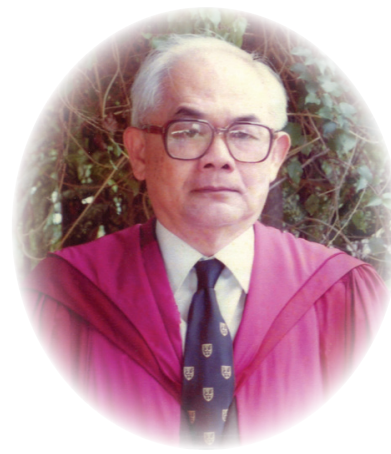

Like many others, I am greatly saddened by Prof Lee Yong Kiat's passing. He was truly a remarkable man with many talents. It is my singular honour to be able to offer these words in remembrance of my teacher, mentor and friend, Prof Lee - a physician, teacher and counsellor who faithfully gave the best of himself to the medical profession in Singapore for more than five decades.

Prof Lee was born in Singapore on 8 October 1928. As the eldest son in the family, he had to fend for his mother and siblings when they lost their father during the Japanese Occupation, but this did not deter him from his studies. He won the Seow Poh Leng Medal at Anglo-Chinese School for being the top boy in all subjects in the 1947 Cambridge Examination, and secured a scholarship for Medicine at the King Edward VII College of Medicine. In 1954, he graduated MBBS with distinction in Medicine.

Five years later, he obtained his Membership of the Royal Colleges of Physicians (MRCP), London and Edinburgh on his first attempt, no mean feat even by today's standards. Fittingly, his wife Chye Neo and son Jonathan (who was only two years old then) were by his side in the UK. Mrs Lee recalled that on passing the MRCP, Prof Lee sent a telegram to his father-in-law informing him of his success, and unabashedly wrote, "Please send money for celebration." His father-in-law duly complied. From my observations, the skill that he developed in managing his fatherin-law is not readily evident in Singapore today.

On his return to Singapore, Prof Lee began his clinical career as a senior registrar in Internal Medicine, before changing course to take up medical administration, and later became Medical Superintendent at Tan Tock Seng Hospital and then at Kandang Kerbau Hospital, during the years in which Singapore strode towards independence from colonial rule.

Not one to shy away from testing his limits, he obtained an LLB in 1962, despite the heavy responsibilities of an administrator, becoming the first medical doctor after the war to obtain a law degree from London. I gathered from Prof Lee's own account that he had wanted to reduce his weight and so decided to study during his lunch hour to keep his mind off food. Law was the chosen field of study, and his knowledge of Latin provided him a distinct advantage. He also found the time to complete his MD thesis in 1965, titled "Non-medical aspects of induced abortion in Singapore".

After 1965, Prof Lee decided to return to clinical Medicine. I am unaware of the reasons for this return, but can only surmise that perhaps it was the calling of Medicine that prompted him, a "physician's instinct", if you will.

Prof Lee returned to serve as physician under Dr Gwee Ah Leng in the newly created Medical Unit III in Singapore General Hospital. In 1971, he became Chief of Medicine of Toa Payoh Hospital till 1988, where he taught medical and dental undergraduates, as well as postgraduates for two decades, and was made Clinical Professor of Medicine. During this time, he also groomed a whole generation of medical leaders. These included Chee Yam Cheng, Walter Tan, Ho Kok Tong, Arthur Tan, Koh Tian Hai, Ong Yong Yau, Michael Yap and Chua Kit Leng.

I remember him as a popular teacher, but also a quiet and confident leader, selfless in his regard for others. Rare was the clinician-leader who could make bedside tutorials fun, interesting and beneficial to the students and trainees with a unique style of his own.

Allow me to paint a mental picture of a typical tutorial of Prof Lee's:

The tutorial begins, and Prof Lee appears with the students' personal record cards, and asks them to draw two cards from the stack. The students whose cards were drawn become candidates for the tutorial. Prof Lee then introduces a medical officer trainee, who is the "examiner" for the tutorial (this trainee would have selected the cases beforehand, verified the physical signs, and researched and read up about them). Prof Lee would encourage the "examiner" to question the student candidates, and then encourage the students in turn to question the "examiner" at session's end, with all parties then given feedback by Prof Lee at the end of the tutorial.

I remember these sessions as being so unique and valuable in the way they seamlessly blended undergraduate and postgraduate teaching, while emphasising the learning process by effective and innovative teaching and mentorship.

I also recall, as many of my peers do, how generous Prof Lee was with students. At the end of the posting, they were typically invited to a departmental dinner that he paid for. He was also known as a kind and nonthreatening examiner, and many 
students fervently desired him for examiner at their final MBBS. However, during his career, Prof Lee did fail a few students who were, in his words, "So bad that it is only fair to the patient and the profession that they spend a further six months brushing up their Medicine."

Prof Lee was well regarded in the medical community, and served in the University Council, the Singapore Medical Council (where he was the Chairman of Preliminary Proceedings Committee), and many Ministry of Health committees. For his contributions to the medical community, he was awarded the SMA Honorary Membership, the Public Administration Medal (Silver and Gold), and the Long Service Medal.

Prof Lee also contributed extensively to our understanding of the history of Medicine in Singapore. This was his pride and passion. He honed and developed consistently, with 96 publications to his name. I recall at the NUS medical school's 100th anniversary celebrations in 2005, Prof Lee prepared 11 papers that included the early history of Anaesthesia, Pathology, Radiology, physicians, pharmacists, private practitioners and private hospitals, specialised nursing, the coroner, infanticide, and registration of births and deaths in early Singapore, the 1926 General Hospital, and the founding of the medical school in 1905. What value did he see in writing medical history? Did he see history as Joseph Priestley did, as "an acquaintance with destiny (that) is agreeable to us as socialise and conversable creatures", or did he, like John Locke, believe that history was a great moral and political teacher? For those of us who understand him, it should be the latter.

Prof Lee was crucial in helping build Changi General Hospital's $(\mathrm{CGH})$ foundation in medical care and clinical teaching, and was made Emeritus Consultant at $\mathrm{CGH}$. It is a testament to Prof Lee's selfless regard for others that even though he had already been in retirement for some time, he continued, over the last ten years, to look after the patients under his care and took an active interest in clinical teaching in $\mathrm{CGH}$.

Prof Lee married Chye Neo, and they had three children and five grandchildren. He had been as much a family man, loving father and doting grandparent, as he had been a physician extraordinaire, teacher, administrator and medical historian. But above all, Prof Lee will be fondly remembered by all of us as a humble, warm and humorous human being who possessed that rare quality of wisdom, which comes from knowledge and deep understanding of human nature. Prof Feng Pao Hsii, who worked with Prof Lee in Toa Payoh Hospital, described him as one with "liberating minds that allow a junior to soar". Like Feng Pao Hsii and many others who were at Prof Lee's wake, we are most grateful to Prof Lee and will miss his wise words.

\section{PROFILE}

Prof Fock Kwong Ming is Assistant Chief Executive Officer, Integrated Care (Clinical) at Eastern Health Alliance. 